\title{
Juxtavascular Microglia Scavenge Dying Pericytes and Vascular Smooth Muscle Cells in Diabetic Retinopathy
}

\author{
Tom A. Gardiner $1, *\left(\mathbb{D}\right.$ and Alan W. Stitt ${ }^{2}$ \\ 1 School of Medicine, Dentistry \& Biomedical Sciences, Queen's University Belfast, Belfast BT9 7BL, UK \\ 2 McAuley Professor of Experimental Ophthalmology, Centre for Experimental Medicine, \\ Queen's University Belfast, Belfast BT9 7BL, UK; a.stitt@qub.ac.uk \\ * Correspondence: t.gardiner@qub.ac.uk
}

Citation: Gardiner, T.A.; Stitt, A.W. Juxtavascular Microglia Scavenge Dying Pericytes and Vascular Smooth Muscle Cells in Diabetic Retinopathy.

Int. J. Transl. Med. 2022, 2, 41-50.

https://doi.org/10.3390/

ijtm2010004

Academic Editor: Winfried

M. Amoaku

Received: 8 November 2021

Accepted: 17 January 2022

Published: 19 January 2022

Publisher's Note: MDPI stays neutral with regard to jurisdictional claims in published maps and institutional affiliations.

Copyright: (c) 2022 by the authors. Licensee MDPI, Basel, Switzerland This article is an open access article distributed under the terms and conditions of the Creative Commons Attribution (CC BY) license (https:// creativecommons.org/licenses/by/ $4.0 /)$.

\begin{abstract}
Diabetic retinopathy (DR) remains a prevalent complication of diabetes and a major cause of vision loss among the working population. Selective loss of pericytes and vascular smooth muscle cells (SMCs), the mural cells of the retinal blood vessels, is pathognomonic of the vasodegenerative element of diabetic retinopathy, and recent studies suggest a central role for autophagy-dependent cell death in this pathology. Our first study of archival electron micrographs from diabetic donor retina provided evidence for the involvement of autophagy in mural cell death during DR and the current report extends those observations to the fate of mural cell corpses in the vascular wall. Here we show that the efferocytosis, or phagocytic removal of dying mural cells, is carried out by a population of juxtavascular microglia (JVM). This population of microglia are well-characterised in the brain but previously unreported in the retina. We demonstrate that JVM are distinct from perivascular macrophages as they participate in the glia limitans of the retinal vasculature and constitute an integral component of the neurovascular unit of the retina. Importantly, mural cells undergoing active phagocytic engulfment appeared to represent relatively early stages in autophagy-dependent cell death, suggesting that the more degraded pericyte and SMC corpses, known as "ghosts", have evaded efficient efferocytosis and undergone secondary necrosis. The alternative fates of mural cell corpses in the retinal vasculature may have important implications for inflammatory processes in the vasodegenerative pathology characteristic of DR.
\end{abstract}

Keywords: diabetic retinopathy; retina; retinal vasculature; pericytes; vascular smooth muscle; cell death; autophagy; efferocytosis; phagocytosis

\section{Introduction}

Diabetic retinopathy (DR) continues to represent the most common complication of diabetes and a major cause of vision loss among the working population [1]. The premature death of the pericytes and vascular smooth muscle cells of the retinal vasculature represents one of the pathognomonic features of the vasodegeneration that accounts for much of the sight loss in DR [2,3]. For many years apoptosis was assumed to be the only mode of cell death involved in the loss of these mural cells in DR [4,5]. Indeed, the morphology of the "ghost" cells that could be found within the basement membrane (BM) of the vascular walls has been interpreted as some form of post-apoptotic necrosis [6]. However, recent experimental studies have implicated autophagy in the death of pericytes in DR $[7,8]$, and provoked re-evaluation of what we know about the death process in mural cells. We therefore re-analysed archival electron micrographs of retinas from diabetic dogs and human donors with diabetes and found significant evidence for the involvement of autophagy in mural cell death [6]. The current report reveals additional new evidence from human retina, that dying mural cells showing excessive autophagy can be phagocytosed by juxtavascular microglia (JVM) that have penetrated the vascular BM. Such activity by microglia has not been previously described in DR and raises questions concerning 
alternative fates for dying mural cells in this disease. We also describe the ultrastructural features of the JVM and present evidence that they constitute an integral component of the neurovascular unit in the retina [9].

\section{Methods}

Archival electron micrographs were analysed from the central retina of single eyes from 4 insulin-dependent alloxan-streptozotocin-induced diabetic dogs, 3 insulin-dependent spontaneously diabetic dogs and 6 human donors who had suffered from diabetes. The exact duration of diabetes in the spontaneous diabetic dogs was uncertain although the animals had been diabetic for 4-6 years; euthanasia was because of failing health and poor condition. At enucleation, $10 \%$ phosphate-buffered formalin was used for initial preservation of the eyes with further fixation in glutaraldehyde prior to dissection. Alloxanstreptozotocin diabetes was induced by simultaneous intravenous administration of the drugs as previously described [10]. A state of moderate hyperglycaemia (mean blood sugar $20 \pm 5 \mathrm{mM} / \mathrm{L}$ ) was maintained for 5 years by daily administration of a single injection of long-acting porcine insulin. The eyes from the experimental diabetic dogs were fixed in $2.5 \%$ glutaraldehyde in either $0.1 \mathrm{M}$ phosphate or $0.1 \mathrm{M}$ cacodylate buffer at $\mathrm{pH} 7.4$.

Diabetic human donor eyes $(n=6)$ that had been obtained withing $6 \mathrm{~h}$ of death were provided by ophthalmologists in Ireland and the UK in the period 1979-1989 in compliance with the Treaty of Helsinki 1964 and permission of local ethical committees. The age range of the donors was 55-69 years, and they all had a diagnosis of type-2 diabetes. The known duration of diabetes for 2 of the donors, aged 55 and 57, was under 1 year, but the period of diabetes in the remaining eyes was unknown. None of the donors suffered from proliferative diabetic retinopathy (PDR). The eyes were transported and stored in $10 \%$ phosphate-buffered formalin and further fixed for $24 \mathrm{~h}$ in $2.5 \%$ glutaraldehyde before dissection.

Dissection was performed with a stereomicroscope and at least 6 tissue samples of the non-macular posterior retina were post-fixed in $1 \%$ osmium tetroxide before ethanol dehydration and embedding in Spurr's resin. The tissue blocks comprised the full thickness of the retina and choroid and were orientated to provide vertical sections of the neural retina and retinal pigment epithelium. Eyes with uninvolved retina that had been enucleated because of anterior segment tumours were used as a source of control tissue; male patients aged 34, 53 and 58 years. The tissue was well preserved as the eyes were placed in 10\% formalin in the operating room. Further fixation was performed as described for donor eyes. Tissue blocks for electron microscopy were dissected from the posterior pole of the superior calottes removed from whole-eye specimens of surgical enucleations prior to wax histology. Processing for electron microscopy was as described for donor eye specimens. For viewing by electron microscopy, silver sections were mounted on copper grids and stained with $2 \%$ uranyl acetate and Reynold's lead citrate.

Electron micrographs for inclusion in the study were selected using a light box and magnifying loop and analysed following digitisation with an Epson Perfection V500 film scanner. A pool of 291 electron micrographs of human retina and 116 from diabetic dogs were available for analysis. However, it should be emphasized that the micrographs of retinal blood vessels in this collection were not randomly chosen. Vascular profiles generally excluded oblique or ambiguous orientations and was enriched in images with identifiable pathology. As autophagy was the principal interest of the present study, it should be clearly understood that at the time of the original studies, autophagy was not considered as a possible precursor of cell death. Therefore, occasional autophagic bodies would not have been considered pathological and only imaged if they occurred in otherwise altered cells or if unusually prominent in terms of complexity or volume. Consequently, it was impossible to carry out quantitative studies and statistical analysis on changes to the background level of autophagy in retinal vascular cells as a result of diabetes. 


\section{Results}

Electron micrographs from diabetic donor retinas frequently showed autophagic vacuoles enclosed by intact cytoplasmic processes within the BM of both large and small retinal vessels (Figure 1). However, the identity of the cells involved remained ambiguous until fortuitous sections revealed the engulfment of an autophagosome-filled pericyte "ghost" (PG) by a juxtavascular microglial cell (JVM) (Figure 1A-D). The JVM cell had free access to the BM as it occupied a major portion of the glia-limitans. The cytoplasm engulfing the PG shows clear continuity with that of the JVM (Figure 1A,B) and a deeper profile reveals the open jaws formed by the phagocytic pseudopodia (Figure 1C,D). Interestingly, the JVM also showed well-developed hemi-desmosome-like attachment plaques to the vascular BM (Figure 1B,D), with that depicted in Figure 1D having an unusual arrangement with 2 adjacent plaques attached to the same tag of the basal lamina (arrows). The cytoplasm of the JVMs was typically paler than the adjacent macroglia of the glia-limitans, and although scattered glycogen particles were common, the JVM lacked the excessive glycogen deposits that accumulate in the macroglia during diabetes. JVM had numerous profiles of rough endoplasmic reticulum and the cell nucleus was typically located close to the vascular BM (Figure 1A-F); these features were consistent with JVM cells in normal retina (discussed below). The locations of the JVM cell bodies tended to coincide with remnants of mural cell death within the vascular BM, suggesting that the cells may have been attracted to these specific sites. Interestingly, JVM cell bodies were also present in the proximity of pericyte processes engaged in excessive autophagy (Figure 1F). JVM cells typically showed residual dense bodies (arrows), presumed to represent the remnants of lysosomal activity, both in diabetic (Figure 1F) and normal donor retinas (discussed below); they also contained discrete aggregates of smaller round to oval granules, $120-150 \mathrm{~nm}$ in diameter, with the characteristics of storage granules (Figure 1F). The development of the RER in some JVM cells was more prominent than that previously described in microglial cells (Figure 1F).

We have described fusiform ghost-cell remnants of vascular smooth muscle cells in the retinal arterioles of diabetic human donors and diabetic dogs after 5 years of diabetes [2,6]. The death process in these cells was assumed to involve autophagy as the cytoplasm was filled by heterogenous membranous vesicles and vacuoles. However, the possible fates of the cell corpses in such locations remains unclear. It was therefore of special interest to identify a retinal arteriole where a cell showing the shrunken electro-dense cytoplasm that typifies apoptosis, combined with excessive autophagy, was apparently undergoing phagocytosis by a JVM cell (Figure 2A-D). Two different Z-planes of the process were available, and the nucleus of the JVM cell is present in the plane captured in Figure $2 C, D$. Furthermore, a group of the presumptive storage granules described above were present in the JVM cytoplasm adjacent to the forming phagosome (Figure 2C). The dying cell has the smooth outline of a large apoptotic body and appears to have been drawn through a break in the outer lamina of the vascular BM (arrows in Figure 2B,C). The profile of the dying cell depicted in Figure 2A,B contains a double-membrane enclosed body filled with textured electron-dense material thought to represent nuclear degraded chromatin $(\mathrm{Ch})$, while the remainder of the cytoplasm is filled with typically heterogeneous autophagosomes (Ap) and coarse aggregates of glycogen granules (Gy). It is unclear how advanced the process of cell death was in the dying cell described, although the presence of a C-shaped double membrane structure (arrow in Figure 2D) suggests that new phagophores were still forming at the point of fixation. The identity of this cell is also uncertain; however, its content of coarse glycogen deposits mirrors those in the adjacent smooth muscle cells (SMCs), and as SMCs are the dominant cell population in the walls of retinal arterioles, it most probably represents the remains of a dying SMC. In comparison with the homogeneous distribution of stored glycogen in the surrounding macroglial processes $(G)$, the glycogen deposits in the SMCs appeared disruptive and were often associated with lipid droplets and lysosomelike bodies (ringed in Figure 2A, with enlargements of the glycogen deposits from four different SMCs in Figure 2E). Some SMCs from other retinal arterioles showed larger glycogen deposits than those in the vessel described above, such as that in the perinuclear 
region of the cell depicted in Figure 2F. The predominance of such glycogen accumulations and associated autophagy in the vascular smooth muscle was interpreted as evidence of diabetes-associated pathology.
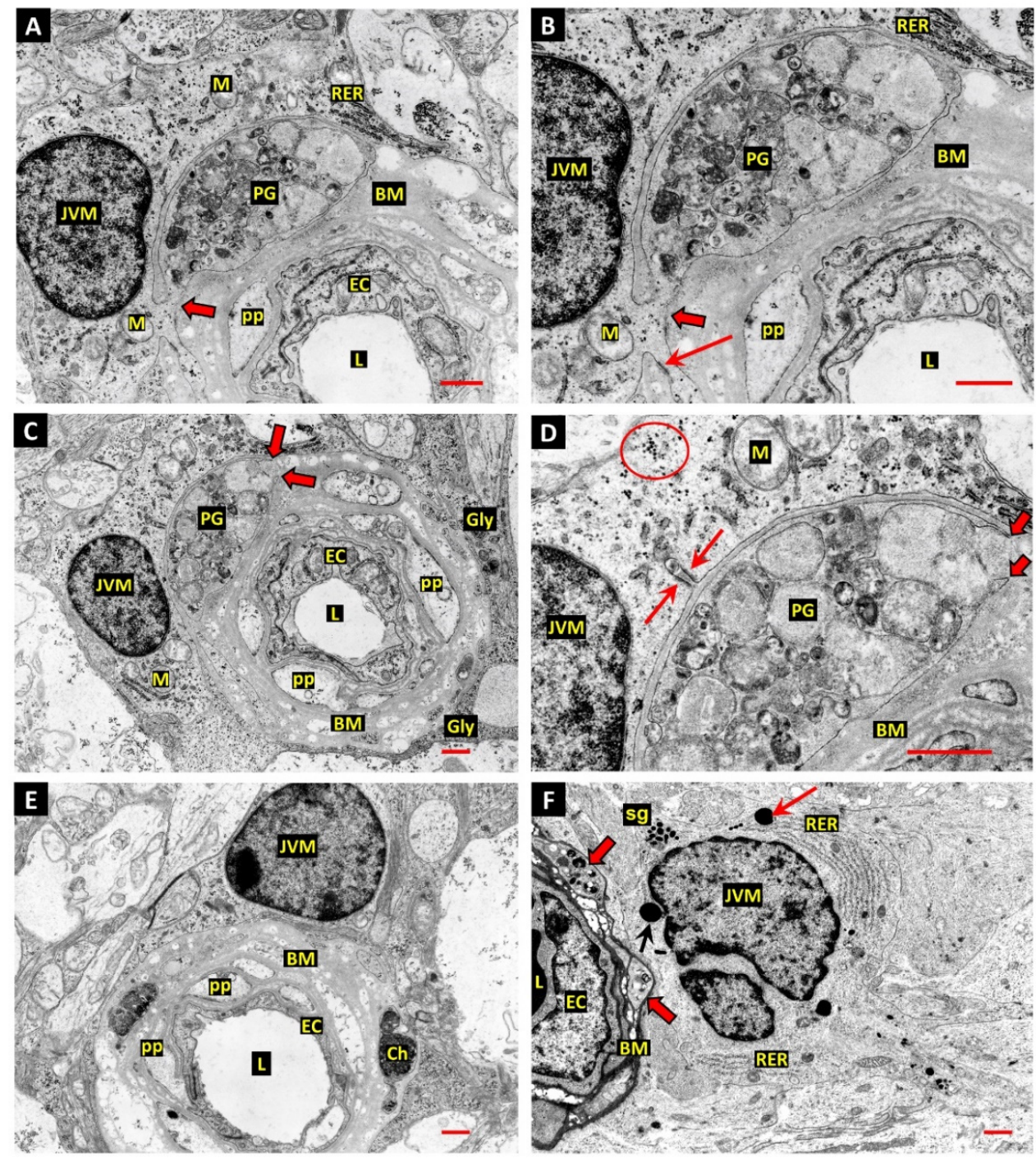

Figure 1. $(\mathbf{A}, \mathbf{B})$ Electron micrograph of a retinal capillary from a diabetic donor eye shows a pericyte "ghost" (PG) filled with vacuolar remnants of extreme autophagic activity within the vascular basement membrane (BM). The PG is undergoing phagocytosis by a perivascular microglial cell (JVM). The process of the JVM engaged in phagocytosis has infiltrated the BM but shows cytoplasmic continuity with the cell of origin (thick arrow). An adjacent process of the JVM shows anchorage to the BM via a well-developed hemi-desmosome-like attachment plaque (arrow, panel B). The JVM shows distinctive aggregates of rough endoplasmic reticulum at the periphery of the cell body (RER). Vascular lumen $-\mathrm{L}$; endothelial cells-EC; pericyte processes— $\mathrm{pp}$; mitochondria- $\mathrm{M}$; bars $1.0 \mu \mathrm{m}$. $(\mathbf{C}, \mathbf{D})$ The deeper Z-plane of retinal capillary depicted in panels A,B provides additional detail of PG phagocytosis by the JVM cell. The extremity of the JVM process engaged in PG engulfment shows the tapered double-membrane ends of phagocytic pseudopodia (thick arrows). This profile also revealed an interesting form of matrix attachment by the JVM cell: 2 of the hemidesmosome-like attachments observed in panels A,B are anchored on the same tag of basal lamina (arrows). The cytoplasm of JVM was typically paler and lacked the dense aggregates of stored glycogen observed in the adjacent macroglia end-feet of the glia limitans (Gly in panel C). However, discrete groups of glycogen particles were common throughout the JVM cytoplasm (ringed in panel D). Bar $1.0 \mu \mathrm{m}$. (E) Another example of a JVM cell, which has commonalities with that depicted in panels $\mathbf{A}, \mathbf{B}$, showing 
the occupancy of a major portion of the glia-limitans surrounding the capillary. Typical also of the microglia in this juxtavascular location is that the cell nucleus lies close to the vascular BM. Two autophagic bodies at the outer edge of the BM have been enclosed by cell processes, presumed to associated with the JVM cell. One of these bodies contains textured electron-dense material, which may represent nuclear chromatin $(\mathrm{Ch})$, noted here because identifiable chromatin remnants were not common in this study. Bar $1.0 \mu \mathrm{m}$. (F) Small retinal vessel from a short-term diabetic donor shows pericyte processes filled with autophagic bodies (thick arrows), and an adjacent JVM cell. The JVM cell contains several residual dense bodies (arrows), presumed to represent the remnants of lysosomal activity, and groups of smaller round-to-oval granules 120-150 $\mathrm{nm}$ in diameter with the characteristics of storage granules (sg). The perinuclear cytoplasm contains two large expanses of rough endoplasmic reticulum (RER). Bar $1.0 \mu \mathrm{m}$.
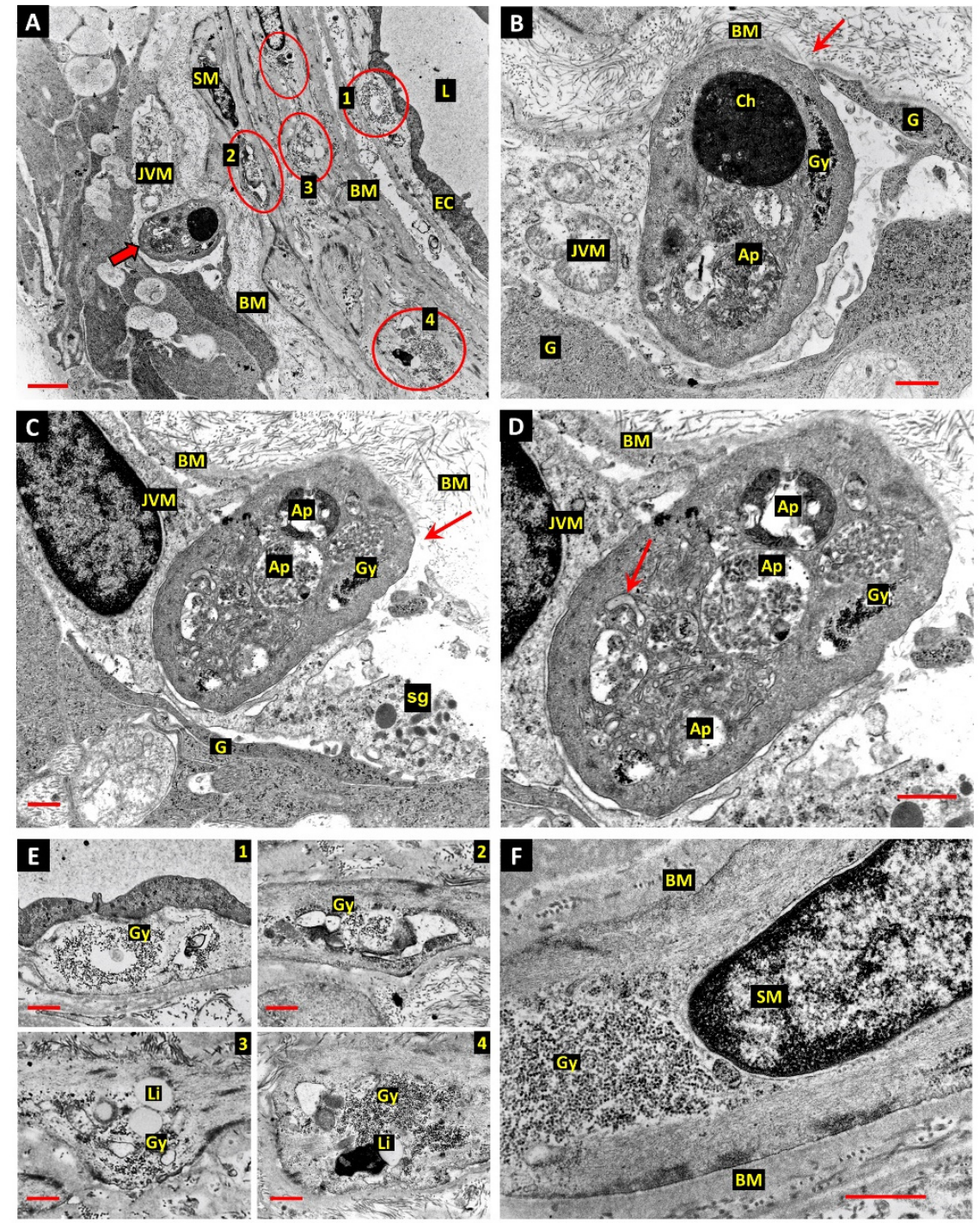

Figure 2. (A) The wall of a retinal arteriole from a diabetic donor eye shows a JVM cell during engulfment of a cell thought to be engaged in either apoptotic or autophagy-dependent cell death (thick arrow). Glycogen deposits in smooth muscle cells (SM) are circled-see enlargements in panel E below. Bar $3.0 \mu \mathrm{m}$. (B) The JVM cell appears to have drawn the dying cell through a break in the outer lamina of the vascular BM (arrow, also in panel C). The cytoplasm of the dying cell contains autophagosomes containing degraded chromatin (Ch), other more typically heterogeneous material (Ap) and coarse aggregates of glycogen granules (Gy). Glial process-G; bar $1.0 \mu \mathrm{m}$. (C) This profile shows the nucleus of the phagocytic JVM cell and a group of the presumptive storage granules in the JVM cytoplasm adjacent to the forming phagosome. Glial process $-\mathrm{G}$; storage granules—sg; bar $1.0 \mu \mathrm{m}$. 
(D) Enlargement of the profile of a dying cell in panel C shows a C-shaped double membrane structure (arrow in panel D), suggesting that new phagophores were still forming at the time of fixation. Bar $1.0 \mu \mathrm{m}$. (E) Four of the glycogen deposits in the SMCs ringed in panel A were associated with lipid droplets (Li) and lysosome-related dense bodies. (F) Extensive perinuclear glycogen deposit in arteriolar SMCs from a different diabetic donor than those described in panels A,E. Bar $1.0 \mu \mathrm{m}$.

The JVM cells involved in the phagocytosis of dead and dying mural cells in the present study have not been previously described in the retina and so their presence in normal retina was confirmed. As it is possible that such cells could be confused with vascular pericytes in forms of microscopy with less resolution than the electron microscope, the JVM cell depicted in Figure 3A,B is important. The cell nucleus and soma of the JVM in this image lie in the same plane as the nuclei of a vascular pericyte and the adjacent endothelial cell of the capillary. The extensive participation of the JVM in the glia limitans is indicated by arrowheads in Figure 3B. Another example of a JVM from a normal retina does not show unambiguous contact with the $\mathrm{BM}$, but the nucleus is characteristically located close to the vessel, with the cytocentrum, identified by a centriole and extensive Golgi apparatus $(\mathrm{Ga})$, located laterally (Figure 3D). Lysosome-associated dense bodies were present in the perinuclear cytoplasm of the majority of JVM cells identified in either diabetic or normal retina (arrows in Figure 3A-D). The presumptive storage granules described in the JVM of the diabetic retina were also present in cell processes of JVM in the normal retina (Figure 3E), as were well-developed stacks of RER (Figure 3F).
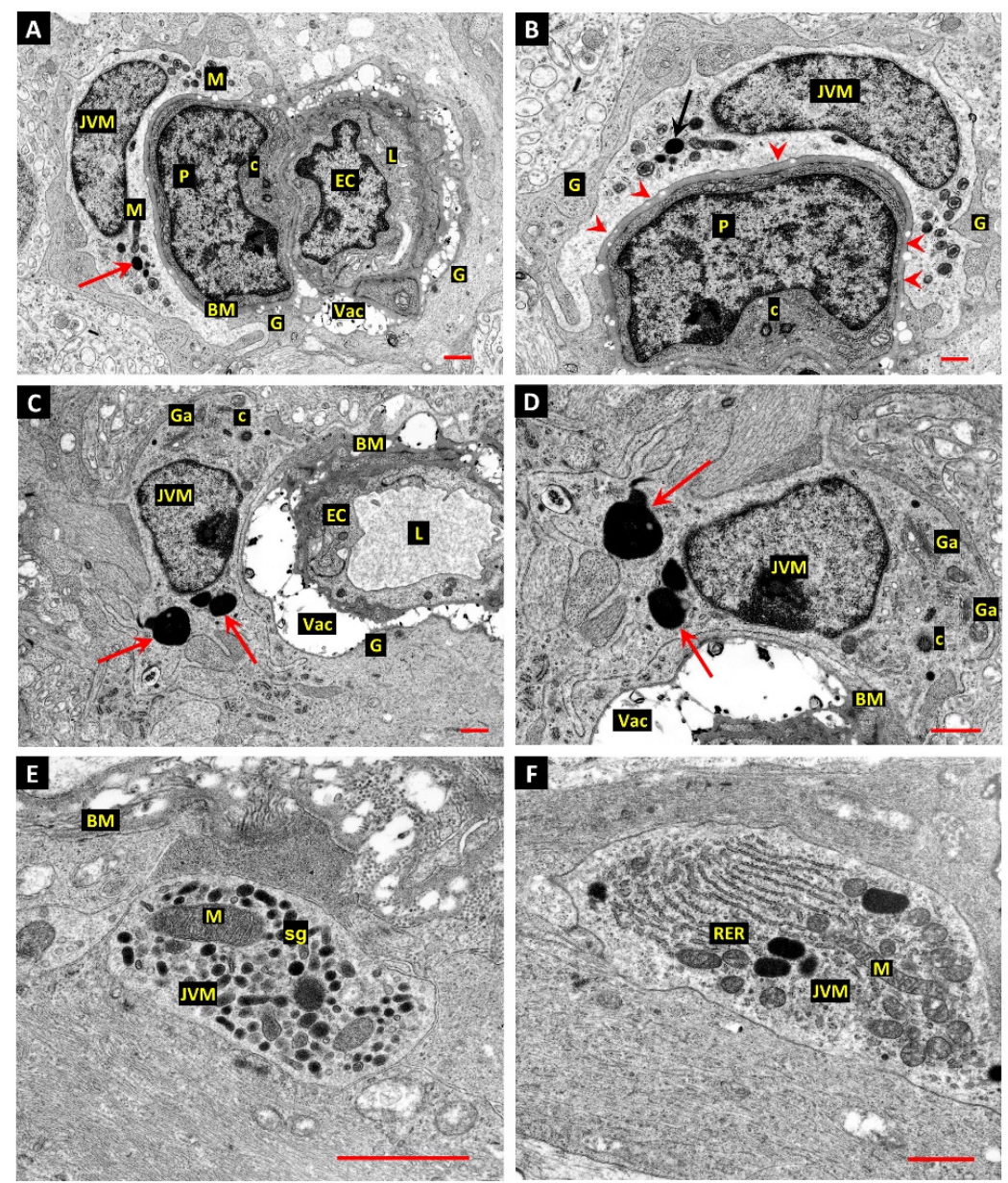

Figure 3. (A,B) Normal donor retina shows the nuclei and perinuclear cytoplasm of a JVM in the same profile as a vascular pericyte (P) and endothelial cell (EC). As in the diabetic retina, the cell nucleus of the JVM cell typically lies close to the vascular BM, a feature also seen in the JVM cell shown in panels C,D. The extensive participation of the JVM in the glia limitans is indicated by 
arrowheads in panel B. The matrices of the mitochondria in the JVM cell are unusually electronopaque, which may be a result of fixation-delay in this particular specimen (M). The typical agerelated BM vacuoles of human retinal capillaries was present (Vac) in this, and all profiles recorded from this material. Arrows-lysosome-related dense body; centrioles-C; vascular lumen-L; glial processes-G; bar $1.0 \mu \mathrm{m}$. (C,D) Another example of a JVM from a normal retina that does not show unambiguous contact with the BM, but the nucleus is characteristically located close to the vessel, with the cytocentrum, identified by a centriole (C) and extensive Golgi apparatus (Ga), located laterally (panels C,D). Lysosome-associated dense bodies were present in the perinuclear cytoplasm of this cell and the majority of JVM identified in either the diabetic or normal retina (arrows in panels A-D). Note that the BM vacuoles (Vac) often expand under the electron beam so that the apparent volume of these features is artefactual. Bar $1.0 \mu \mathrm{m}$. (E,F) The presumptive storage granules (sg) described in the JVM of the diabetic retina were also present in cell processes of JVM in the normal retina (panel E, bar $1.0 \mu \mathrm{m}$ ), as were well-developed stacks of RER (panel F, bar $1.0 \mu \mathrm{m}$ ).

\section{Discussion}

This study has provided further evidence for the involvement of excessive autophagy in the death of pericytes and vascular SMCs in DR. We also show that mural cells undergoing such death may be scavenged from the vascular wall through the phagocytic actions of JVM. However, it is obvious that such sequestration of dying mural cells represents only one possible fate for their corpses. It was notable in the examples presented in this study that the contents of the dying cells undergoing phagocytosis were relatively well preserved, as judged by the preservation of the autophagosomes and their limiting membranes. In contrast, some of the pericyte and SM ghost cells shown in our previous work [6] appeared in a later state of necrosis-like degeneration, with no evidence of attempts to scavenge their contents by local cells or professional phagocytes. Indeed, it is possible that the relatively early stage of the death process in the examples shown accounts for their efficient phagocytosis by JVM cells. On this issue, it is significant that the presumptive SMCs undergoing phagocytosis from the arteriolar wall showed a mixed ultrastructure of apoptosis and excessive autophagy, with continued evidence of active autophagy. Therefore, this cell appears to have initiated its own phagocytosis prior to the completion of the death process. This conclusion is consistent with the current paradigm whereby dying cells release paracrine "find me" signals, such as ATP or fractalkine/CX3CL1 [11], that may be detected by the respective purinergic or CX3CR1 receptors carried by microglia and macrophages [12-14]. The process starting with the release of "find me" signals and ending with completion of phagocytic engulfment has been termed efferocytosis [15], and out of necessity, the timely detection of "find me" signals requires the presence of JVM cells in the local neurovascular unit. However, the distribution of JVM may be inconsistent in different regions of the retina, so that some dying mural cells may be efficiently scavenged while others undergo necrotic degeneration [16]. Clearly these different outcomes have significant implications for local neurovascular inflammation, as apoptosis is regarded as a non-inflammatory mode of cell death while the various modes of necrosis are invariably pro-inflammatory [17,18]. Inefficient clearance of apoptotic corpses may result in post-apoptotic or secondary necrosis, a process linked to both acute and chronic inflammation [16]. In the context of the retinal microvasculature, inefficient clearance of mural cell corpses may incite local inflammatory responses in the adjacent endothelium [19], thus increasing the likelihood of inflammatory endothelial pathology such as leukostasis [20].

The JVM cells described effecting the phagocytosis of dying pericytes and SMCs in the current study do not appear to have been previously described in the retina, although perivascular macrophages have been characterised in the retina as having a scavenger function at the blood-retinal barrier [21]. The cells involved were differentiated from microglia on the basis that they failed to stain with the microglial immunomarker Iba- 1 and on electron microscopy were found to reside on the vascular side of the glia limitans [21]. In contrast, the JVM cells in the present study were found to constitute an integral part of the glia limitans, in the same way as the juxtavascular microglia described in the brain $[22,23]$. 
Juxtavascular microglia have been reported in the brain for at least 25 years [24-28], and have been described as a stable population that shows little turnover with other marrowderived macrophages $[24,28]$, but which can exhibit dynamic activity, with the ability to migrate along the microvessels to access sites of injury [26]. Remarkably, a recent study has identified an important role for juxtavascular microglia in restoration of the blood-brain barrier following laser injury, with microglial processes moving to physically seal the sites of damage in the vascular endothelium [25]. This activity was found to be mediated by their P2RY12 purinergic receptors and the authors concluded that the juxtavascular microglia constitute an integral component of the neurovascular unit [25].

Several studies have described perivascular microglia in the retina under pathological conditions and ageing [29-31], but lacked the correlative light-electron microscopic approach employed in the study by Mendes-Jorge et al. [21], and were therefore unable to precisely localize the cells of interest in relation to the blood-retinal barrier and the glia limitans. Confocal microscopy has revealed a population of lipofuscin-containing microglia in close apposition to the retinal vessels in aged mice [31] that appear sufficiently numerous to correspond to the JVM cells described in the present study. Furthermore, the lysosomal-like dense bodies that were common in the JVM of the present study may contain lipofuscin. However, further correlative LM-EM studies will be required to confirm a common identity and a role in DR.

The high level of glycogen deposition in arteriolar SMCs observed in the current study warrants comment: Glycogen is the principal form of stored carbohydrate in animal cells and may be mobilised by two recognised mechanisms. Firstly, through the action of glycogen phosphorylase and a debranching enzyme, to enter the metabolism as glucose-1-phosphate [32]; and secondly, through an autophagic pathway, specifically termed glycophagy $[33,34]$, terminating with the release of glucose from the lysosomes through the action of acid alpha-glucosidase [32]. The association of the glycogen deposits observed in the arteriolar SMCs with autophagic bodies and lipid droplets suggests that an autophagic mechanism is involved in the glycogen metabolism of these cells in diabetes; however, whether the deposits observed were subject to glycophagy or macro-autophagy is unknown. Glycogen represents a vital energy substrate in vascular smooth muscle [35,36], although pathological or even increased accumulation of glycogen has not been reported in SMCs in diabetes. However, pathological glycogen storage has been well-characterised in cardiac muscle and is known to be regulated by insulin in the presence of hyperglycaemia [37]. Interestingly, cardiac myocytes accumulate glycogen in spite of significantly increased expression of the proteins associated with glycophagy, suggesting diabetesrelated dysfunction in glycogen turnover. In the SMCs of retinal arterioles in the current study, the coarse irregular glycogen deposits appeared to disrupt the fine organisation of the microfilament bundles that occupy the greater part of the sarcoplasm in normal SMCs. Whether the physical presence of excessive glycogen can induce cellular dysfunction or whether it can incite excessive autophagy, leading to cell death, will require targeted studies that take glycogen storage into account in diabetic retinopathy. The present investigation has shown increased glycogen content in the retinal macroglia and vascular smooth muscle, and our previous work has demonstrated abnormal glycogen accumulations in the retinal amacrine cells in DR [38]. Unfortunately, glycogen is a labile substance, and its presence can only be detected by histochemical staining in well-fixed tissues. Therefore, to correctly address the role of this important carbohydrate in DR will require studies and methods that preserve the subject material.

Our first study of archival electron micrographs of diabetic retinas sought to document evidence for the involvement of autophagy in the cell death of pericytes and vascular SMCs in DR [6]. The current study has added to that evidence and identified the role of JVM cells in the fate of mural cell corpses in DR. We also document the ultrastructural features of JVM in the retina and propose that these cells be included as a fundamental component of the neurovascular unit in the retina. Finally, we have provided evidence that diabetes-related 
accumulation of glycogen in arteriolar SMCs may represent both a new pathology and a possible trigger for autophagy.

Author Contributions: Formal analysis, T.A.G.; writing-original draft preparation, T.A.G.; writing-review and editing, A.W.S. All authors have read and agreed to the published version of the manuscript.

Funding: This research received no external funding.

Institutional Review Board Statement: This study was performed on anonymous archival data so no institutional ethical approval was required.

Informed Consent Statement: Not applicable.

Data Availability Statement: The study involved qualitative evaluation of electron micrographs. No numerical data was produced.

Conflicts of Interest: The authors declare no conflict of interest.

\section{References}

1. Antonetti, D.A.; Klein, R.; Gardner, T.W. Diabetic retinopathy. N. Engl. J. Med. 2012, 366, 1227-1239. [CrossRef] [PubMed]

2. Gardiner, T.A.; Stitt, A.W.; Anderson, H.R.; Archer, D.B. Selective loss of vascular smooth muscle cells in the retinal microcirculation of diabetic dogs. Br. J. Ophthalmol. 1994, 78, 54-60. [CrossRef] [PubMed]

3. Cogan, D.G.; Toussaint, D.; Kuwabara, T. Retinal vascular patterns., I.V. Diabetic retinopathy. Arch. Ophthalmol. 1961, 66, 366-378. [CrossRef] [PubMed]

4. Mizutani, M.; Kern, T.S.; Lorenzi, M. Accelerated death of retinal microvascular cells in human and experimental diabetic retinopathy. J. Clin. Investig. 1996, 97, 2883-2890. [CrossRef] [PubMed]

5. Behl, Y.; Krothapalli, P.; Desta, T.; DiPiazza, A.; Roy, S.; Graves, D.T. Diabetes-enhanced tumor necrosis factor-alpha production promotes apoptosis and the loss of retinal microvascular cells in type 1 and type 2 models of diabetic retinopathy. Am. J. Pathol. 2008, 172, 1411-1418. [CrossRef] [PubMed]

6. Gardiner, T.A.; Stitt, A.W. Pericyte and Vascular Smooth Muscle Death in Diabetic Retinopathy Involves Autophagy. Int. J. Transl. Med. 2021, 2, 26-40. [CrossRef]

7. Fu, D.; Yu, J.Y.; Yang, S.; Wu, M.; Hammad, S.M.; Connell, A.R.; Du, M.; Chen, J.; Lyons, T.J. Survival or death: A dual role for autophagy in stress-induced pericyte loss in diabetic retinopathy. Diabetologia 2016, 59, 2251-2261. [CrossRef]

8. Fu, D.; Wu, M.; Zhang, J.; Du, M.; Yang, S.; Hammad, S.M.; Wilson, K.; Chen, J.; Lyons, T.J. Mechanisms of modified LDL-induced pericyte loss and retinal injury in diabetic retinopathy. Diabetologia 2012, 55, 3128-3140. [CrossRef]

9. Metea, M.R.; Newman, E.A. Signalling within the neurovascular unit in the mammalian retina. Exp. Physiol. 2007, 92, 635-640. [CrossRef] [PubMed]

10. Anderson, H.R.; Stitt, A.W.; Gardiner, T.A.; Lloyd, S.J.; Archer, D.B. Induction of alloxan/streptozotocin diabetes in dogs: A revised experimental technique. Lab. Anim. 1993, 27, 281-285. [CrossRef]

11. Hochreiter-Hufford, A.; Ravichandran, K.S. Clearing the dead: Apoptotic cell sensing, recognition, engulfment, and digestion. Cold Spring Harb. Perspect. Biol. 2013, 5, a008748. [CrossRef] [PubMed]

12. Blume, Z.I.; Lambert, J.M.; Lovel, A.G.; Mitchell, D.M. Microglia in the developing retina couple phagocytosis with the progression of apoptosis via P2RY12 signaling. Dev. Dyn. 2020, 249, 723-740. [CrossRef]

13. Liang, K.J.; Lee, J.E.; Wang, Y.D.; Ma, W.; Fontainhas, A.M.; Fariss, R.N.; Wong, W.T. Regulation of dynamic behavior of retinal microglia by CX3CR1 signaling. Invest. Ophthalmol. Vis. Sci. 2009, 50, 4444-4451. [CrossRef] [PubMed]

14. Haynes, S.E.; Hollopeter, G.; Yang, G.; Kurpius, D.; Dailey, M.E.; Gan, W.B.; Julius, D. The P2Y12 receptor regulates microglial activation by extracellular nucleotides. Nat. Neurosci. 2006, 9, 1512-1519. [CrossRef] [PubMed]

15. Marquez-Ropero, M.; Benito, E.; Plaza-Zabala, A.; Sierra, A. Microglial Corpse Clearance: Lessons From Macrophages. Front. Immunol. 2020, 11, 506. [CrossRef]

16. Silva, M.T. Secondary necrosis: The natural outcome of the complete apoptotic program. FEBS Lett. 2010, 584, 4491-4499. [CrossRef] [PubMed]

17. Kolb, J.P.; Oguin, T.H., 3rd; Oberst, A.; Martinez, J. Programmed Cell Death and Inflammation: Winter Is Coming. Trends Immunol. 2017, 38, 705-718. [CrossRef]

18. Green, D.R.; Oguin, T.H.; Martinez, J. The clearance of dying cells: Table for two. Cell Death Differ. 2016, 23, 915-926. [CrossRef]

19. Goulopoulou, S.; McCarthy, C.G.; Webb, R.C. Toll-like Receptors in the Vascular System: Sensing the Dangers Within. Pharmacol. Rev. 2016, 68, 142-167. [CrossRef]

20. Miyamoto, K.; Khosrof, S.; Bursell, S.E.; Rohan, R.; Murata, T.; Clermont, A.C.; Aiello, L.P.; Ogura, Y.; Adamis, A.P. Prevention of leukostasis and vascular leakage in streptozotocin-induced diabetic retinopathy via intercellular adhesion molecule-1 inhibition. Proc. Natl. Acad. Sci. USA 1999, 96, 10836-10841. [CrossRef] [PubMed] 
21. Mendes-Jorge, L.; Ramos, D.; Luppo, M.; Llombart, C.; Alexandre-Pires, G.; Nacher, V.; Melgarejo, V.; Correia, M.; Navarro, M.; Carretero, A.; et al. Scavenger function of resident autofluorescent perivascular macrophages and their contribution to the maintenance of the blood-retinal barrier. Invest. Ophthalmol. Vis. Sci. 2009, 50, 5997-6005.

22. Joost, E.; Jordao, M.J.C.; Mages, B.; Prinz, M.; Bechmann, I.; Krueger, M. Microglia contribute to the glia limitans around arteries, capillaries and veins under physiological conditions, in a model of neuroinflammation and in human brain tissue. Brain Struct. Funct. 2019, 224, 1301-1314. [CrossRef]

23. Lassmann, H.; Zimprich, F.; Vass, K.; Hickey, W.F. Microglial cells are a component of the perivascular glia limitans. J. Neurosci. Res. 1991, 28, 236-243. [CrossRef]

24. Mondo, E.; Becker, S.C.; Kautzman, A.G.; Schifferer, M.; Baer, C.E.; Chen, J.; Huang, E.J.; Simons, M.; Schafer, D.P. A Developmental Analysis of Juxtavascular Microglia Dynamics and Interactions with the Vasculature. J. Neurosci. 2020, 40, 6503-6521. [CrossRef]

25. Lou, N.; Takano, T.; Pei, Y.; Xavier, A.L.; Goldman, S.A.; Nedergaard, M. Purinergic receptor P2RY12-dependent microglial closure of the injured blood-brain barrier. Proc. Natl. Acad. Sci. USA 2016, 113, 1074-1079. [CrossRef] [PubMed]

26. Grossmann, R.; Stence, N.; Carr, J.; Fuller, L.; Waite, M.; Dailey, M.E. Juxtavascular microglia migrate along brain microvessels following activation during early postnatal development. Glia 2002, 37, 229-240. [CrossRef] [PubMed]

27. Mato, M.; Ookawara, S.; Sakamoto, A.; Aikawa, E.; Ogawa, T.; Mitsuhashi, U.; Masuzawa, T.; Suzuki, H.; Honda, M.; Yazaki, Y.; et al. Involvement of specific macrophage-lineage cells surrounding arterioles in barrier and scavenger function in brain cortex. Proc. Natl. Acad. Sci. USA 1996, 93, 3269-3274. [CrossRef] [PubMed]

28. Gehrmann, J.; Matsumoto, Y.; Kreutzberg, G.W. Microglia: Intrinsic immuneffector cell of the brain. Brain Res. Brain Res. Rev. 1995, 20, 269-287. [CrossRef]

29. Gregerson, D.S.; Yang, J. CD45-positive cells of the retina and their responsiveness to in vivo and in vitro treatment with IFN-gamma or anti-CD40. Investig. Ophthalmol. Vis. Sci. 2003, 44, 3083-3093. [CrossRef]

30. Gullapalli, V.K.; Zhang, J.; Pararajasegaram, G.; Rao, N.A. Hematopoietically derived retinal perivascular microglia initiate uveoretinitis in experimental autoimmune uveitis. Graefes Arch. Clin. Exp. Ophthalmol. 2000, 238, 319-325. [CrossRef]

31. Xu, H.; Chen, M.; Manivannan, A.; Lois, N.; Forrester, J.V. Age-dependent accumulation of lipofuscin in perivascular and subretinal microglia in experimental mice. Aging Cell 2008, 7, 58-68. [CrossRef] [PubMed]

32. Adeva-Andany, M.M.; Gonzalez-Lucan, M.; Donapetry-Garcia, C.; Fernandez-Fernandez, C.; Ameneiros-Rodriguez, E. Glycogen metabolism in humans. BBA Clin. 2016, 5, 85-100. [CrossRef] [PubMed]

33. Mandl, J.; Banhegyi, G. The ER-Glycogen Particle-Phagophore Triangle: A Hub Connecting Glycogenolysis and Glycophagy? Pathol. Oncol. Res. 2018, 24, 821-826. [CrossRef]

34. Jiang, S.; Heller, B.; Tagliabracci, V.S.; Zhai, L.; Irimia, J.M.; DePaoli-Roach, A.A.; Wells, C.D.; Skurat, A.V.; Roach, P.J. Starch binding domain-containing protein 1/genethonin 1 is a novel participant in glycogen metabolism. J. Biol. Chem. 2010, 285, 34960-34971. [CrossRef]

35. Shi, J.; Yang, Y.; Cheng, A.; Xu, G.; He, F. Metabolism of vascular smooth muscle cells in vascular diseases. Am. J. Physiol. Heart Circ. Physiol. 2020, 319, H613-H631. [CrossRef] [PubMed]

36. Allen, T.J.; Hardin, C.D. Influence of glycogen storage on vascular smooth muscle metabolism. Am. J. Physiol. Heart Circ. Physiol. 2000, 278, H1993-H2002. [CrossRef] [PubMed]

37. Mellor, K.M.; Varma, U.; Stapleton, D.I.; Delbridge, L.M. Cardiomyocyte glycophagy is regulated by insulin and exposure to high extracellular glucose. Am. J. Physiol. Heart Circ. Physiol. 2014, 306, H1240-H1245. [CrossRef]

38. Gardiner, T.A.; Canning, P.; Tipping, N.; Archer, D.B.; Stitt, A.W. Abnormal Glycogen Storage by Retinal Neurons in Diabetes. Investig. Ophthalmol. Vis. Sci. 2015, 56, 8008-8018. [CrossRef] 